\title{
The use of the scintillation technique for monitoring seasonal water consumption of olive orchards in a semi-arid region
}

\author{
J. Ezzahar ${ }^{a}$, A. Chehbouni ${ }^{b, *}$, J.C.B. Hoedjes ${ }^{b}$, S. Er-Raki ${ }^{a}$, Ah. Chehbouni ${ }^{a}$, \\ G. Boulet ${ }^{b}$, J.-M. Bonnefond ${ }^{c}$, H.A.R. De Bruin ${ }^{d}$ \\ a Physics Department, Faculty of Sciences Semlalia, Marrakesh, Morocco \\ ${ }^{\mathrm{b}}$ IRD - Centre d'Etudes Spatiales de la Biosphère, BP 31055 Cedex Toulouse, France \\ c INRA, EPHYSE, Bordeaux, France \\ ${ }^{\mathrm{d}}$ Wageningen University Research Centre, Environmental Sciences Group, Centre for Water and Climate, \\ Meteorology \& Air Quality Group, P.O. Box 47, 6700 AA Wageningen, The Netherlands
}

\section{A R T I C L E I N F O}

Article history:

Accepted 26 December 2006

Keywords:

Large aperture scintillometer

Eddy covariance

Energy balance

Olive

Flood irrigation

Semi-arid region

\begin{abstract}
A B S T R A C T
To monitor seasonal water consumption of agricultural fields at large scale, spatially averaged surface fluxes of sensible heat $(H)$ and latent heat $\left(L_{\mathrm{v}} E\right)$ are required. The scintillation method is shown to be a promising device for obtaining the area-averaged sensible heat fluxes, on a scale of up to $10 \mathrm{~km}$. These fluxes, when combined with a simple available energy model, can be used to derive area-averaged latent heat fluxes. For this purpose, a Large Aperture Scintillometer (LAS) was operated continuously for more than one year over a tall and sparse irrigated oliveyard located in south-central Marrakesh (Morocco). Due to the flood irrigation method used in the site, which induces irregular pattern of soil moisture both in space and time, the comparison between scintillometer-based estimates of daily sensible heat flux ( $\mathrm{H}_{\text {LAS }}$ ) and those measured by the classical eddy covariance (EC) method $\left(H_{\mathrm{EC}}\right)$ showed a large scatter during the irrigation events, while a good correspondence was found during homogenous conditions (dry conditions and days following the rain events). We found, that combining a simple available energy model and the LAS measurements, the latent heat can be reliably predicted at large scale in spite of the large scatter $\left(R^{2}=0.72\right.$ and RMSE $=18.25 \mathrm{~W} \mathrm{~m}^{-2}$ ) that is obtained when comparing the LAS against the EC. This scatter is explained by different factors: the difference in terms of the source areas of the LAS and EC, the closure failure of the energy balance of the EC, and the error in available energy estimates. Additionally, the irrigation efficiency was investigated by comparing measured seasonal evapotranspiration values to those recommended by the FAO. It was found that the visual observation of the physical conditions of the plant is not sufficient to efficiently manage the irrigation, a large quantity of water is lost ( $\approx 37 \%$ of total irrigation). Consequently, the LAS can be considered as a potentially useful tool to monitor the water consumption in complex conditions.
\end{abstract}

C) 2007 Published by Elsevier B.V.

* Corresponding author at: Centre d'Etudes Spatiales de la Biosphère (CESBIO), 18 Avenue Edouard Belin, 31401 Toulouse Cedex 9 , France. Tel.: +335615581 97; fax: +33561558500.

E-mail address: ghani@cesbio.cnes.fr (A. Chehbouni). 0378-3774/\$ - see front matter (C) 2007 Published by Elsevier B.V. doi:10.1016/j.agwat.2006.12.015 


\section{Introduction}

The arid and semi-arid regions constitute roughly one third of the total earth surface. In these regions water scarcity is one of the main limiting factors for economic growth. The impact of such water scarcity is amplified by inefficient irrigation practices, especially since about $85 \%$ of available water is used for irrigation in these regions. In this context, several research programs have been designed to develop tools to support efficient management of irrigation water in arid and semi-arid zones. SUDMED (Chehbouni et al., 2003, 2004) and IRRIMED (http://www.irrimed.org) projects are amongst those programs taking place in the southern Mediterranean region. These projects focus on the assessment of temporal and spatial variability of water needs and consumption of irrigated agriculture under limited water resource conditions. The projects area is located in the Tensift river basin which includes the Haouz plain (near Marrakesh city, Morocco). In the Haouz plain the climate is semi arid and is characterized by low and irregular rainfall. The average amount of rainfall per year is about $240 \mathrm{~mm}$, whereas the evaporative demand is very high - around $1600 \mathrm{~mm}$ per year - according to the FAO method (Allen et al., 1998). Cereals (wheat, barley), olive and citrus orchards are the dominating crops in the plain and use as much as $84 \%$ of the total available water.

Due to its high adaptability to semi-arid climate, olives make up the main component of the orchard in the Houaz plain. Flood irrigation is widely practiced by the majority of the farmers (more than 85\%). Part of the water supplied to the orchard by rainfall and irrigation is effectively consumed by the crop, whereas the remaining is stored in the soil, percolates to deeper soil, or is lost through soil evaporation. In this regard, one can classify the loss in two categories: agronomical loss and hydrological loss. Agronomists consider that all the water which is not used by the plant is lost, while hydrologists judge only the soil evaporation to be lost since the infiltrated water is used to refill the ground water.

The present study focused on estimating seasonal water needs and consumption of a tall and sparse irrigated oliveyard (Agdal). Eddy covariance (EC) technique was used to monitor evapotranspiration, it is proven to be the most accurate method to measure evapotranspiration or latent heat flux: $L_{v} E$ is a local measurement and therefore difficult to use in the case of heterogeneous surfaces, unless a network of EC systems is available which is very costly and require a well trained staff to operate and to maintain it. Moreover, over tall sparse vegetation such as an oliveyard, the variability of local fluxes appears to be large (e.g. Vogtet al., 2004), therefore, strictly speaking severalEC systems are needed, whereas a scintillometer provides an area average. From the view point of the farmer, a scintillometer has the advantage that the receiver and detector are installed at the peripheral of the field and not in the centre. This seriously limits the applicability of such system at the scale of the irrigation district which is the relevant scale for water managers. For these practical reasons it is worth investigating the applicability of scintillometry over this tall sparse vegetating type. As far as we know such a study on scintillometer applicability to large scale water management has never been performed before.

In this context, the scintillation method which can provide either direct or indirect estimates of $L_{\mathrm{v}} E$ along a path length, whose dimensions may range from a few hundred metres up to $10 \mathrm{~km}$ has been considered as an effective way to overcome this difficulty (Chehbouni et al., 1999). Three types of scintillometers are available: radio wave scintillometers (RWS), small aperture (laser) scintillometers (SAS), and large aperture scintillometers (LAS). The RWS, which operates at radio wavelength is the most sensitive to humidity fluctuations (Andreas, 1989) and is more suitable for directly obtaining $L_{\mathrm{v}} E$ over large areas. However, this type of scintillometer is not widely used since its system components are expensive and difficult to operate, moreover some interferences may occur especially close to cities (Meijninger et al., 2002a). Conversely, the LAS which operates in the visible and near-infrared wavelength region of the spectrum is relatively cheap and very robust which makes it suitable for operation in remote fields. This explains the fact that the LAS is regularly used nowadays in micrometeorological experiments (e.g. Chehbouni et al., 2000 (SALSA); Hoedjes et al., 2002 (Yaqui 2000); Hartogensis et al., 2002; Poulos et al., 2000 (CASES-99); Beyrich et al., 2000 (LITFASS-98), and 2006 (LITFASS2003)).

However, the LAS only provides spatially averaged sensible heat flux ( $\left.\mathrm{H}_{\mathrm{LAS}}\right)$. As it has been shown in Meijninger et al. (2002a), latent heat flux $\left(L_{\mathrm{v}} E_{\mathrm{LAS}}\right)$ can then be obtained as the residual term of the energy balance equation providing estimates of available energy $\left(R_{n}-G\right)$, where $\left(R_{n}\right)$ is the net radiation and $(G)$ is the soil heat flux.

In this study the potential of the LAS to derive $L_{v} E_{L A S}$ over a complex field was investigated. The complexity is due to the fact that the vegetation is tall and sparse, which means that transfer processes are more complex than for short and dense crops, and this Monin-Obukhov similarity theory may not apply. Moreover, flood irrigation creates a large heterogeneity in soil humidity, and in some cases advection from the surrounding areas occurred.

The main objective of this paper is two-fold: (1) to combine the LAS measurements with estimates of available energy to derive spatially averaged $L_{\mathrm{v}} E_{\mathrm{LAS}}$, and (2) to investigate the feasibility of using the LAS to monitor seasonal water consumption of olive orchards in the Haouz semi-arid plain and to document irrigation efficiency through the comparison between LAS-based estimates of evapotranspiration values to those recommended by the FAO method (FAO-56). This paper is organised as follows: a brief physical background of the scintillation method and the proposed models to estimate the available energy are first provided. Second, an overview of the experimental design follows with a presentation of the results before presenting comparisons between simulated and observed fluxes. Finally, a discussion about the potential of the LAS combined with the estimated available energy to calculate the $L_{\mathrm{v}} E$ over olive orchards, and the ability of this approach to monitor the water consumption over semi-arid land, is presented.

\section{Theoretical background}

\subsection{Determining the sensible heat flux, $H_{\text {LAS }}$, with LAS}

The LAS is a device that provides measurements of the variation in the refractive index of air caused by atmo- 
spheric turbulence. This instrument consists of a transmitter and a receiver installed at a certain height $z_{\text {LAS }}$ above the surface. The LAS used in this study has an aperture diameter $D$ of $15 \mathrm{~cm}$. The transmitter emits electromagnetic radiation at wavelength $\lambda=940 \mathrm{~nm}$ over a known path length ( $L$ ). The fluctuations in the light intensity at the receiver are analysed to give the variation of $C_{n}^{2}$ along the path.

Hill et al. (1980) has related $C_{n}^{2}$ with the structure parameters of temperature $\left(C_{T}^{2}\right)$, humidity $\left(C_{q}^{2}\right)$ and the covariant term $\left(C_{\mathrm{Tq}}\right)$ as follows:

$C_{n}^{2}=\frac{A_{T}^{2}}{T^{2}} C_{T}^{2}+\frac{A_{T} A_{q}}{T q} C_{T q}+\frac{A_{q}^{2}}{q^{2}} C_{q}^{2}$

where $A_{T}$ and $A_{q}$ are quantities that represent the relative contribution of each term to $C_{n}^{2}$, which are both dependent on optical wavelength and the mean values of temperature ( $T$ ), humidity (q), and atmospheric pressure $(p)$. In the case of the LAS in this project, the values of $A_{T}$ and $A_{q}$ are given by Andreas (1989):

$A_{T}=-0.78 \times 10^{-6} \frac{p}{T}$

$A_{q}=-57.22 \times 10^{-6} q$

Generally, the first term, containing $C_{T}^{2}$, is much larger than the other two terms, except in the case where the Bowen-ratio $\beta\left(=H_{\text {LAS }} / L_{\mathrm{v}} E_{\mathrm{LAS}}\right)$ is much smaller than 1. Assuming that temperature and humidity fluctuations are perfectly correlated, Wesely (1976) showed that the temperature structure parameter $C_{T}^{2}$ can be derived from the refractive index structure parameter $C_{n}^{2}$ by:

$C_{T}^{2}=C_{n}^{2}\left(\frac{T^{2}}{\gamma p}\right)^{2}\left(1+\frac{0.03}{\beta}\right)^{-2}$

where $\gamma$ is the refractive index coefficient for air $\left(7.8 \times 10^{-7} \mathrm{~K} \mathrm{~Pa}^{-1}\right)$. The final bracketed term is a correction for the effects of humidity. $C_{n}^{2}$ and $C_{T}^{2}$ are in $\left(\mathrm{m}^{-2 / 3}\right)$ and $\left(\mathrm{K} \mathrm{m}^{-2 / 3}\right)$, respectively.

According to the Monin-Obukhov Similarity Theory (MOST), it is possible to link the temperature structure parameter $C_{T}^{2}$ and the temperature scale $T^{*}$ for unstable conditions, i.e., $\mathrm{L}_{\mathrm{MO}}<0$ :

$C_{\mathrm{T}}^{2}=\mathrm{T}_{*}^{2}\left(\mathrm{z}_{\mathrm{LAS}}-d\right)^{-2 / 3} h\left(\frac{\left(\mathrm{z}_{\mathrm{LAS}}-d\right)}{\mathrm{L}_{\mathrm{MO}}}\right)$

where $z$ and $d$ are the measurement and displacement height, respectively, $h$ is a universal function. Wyngaard et al. (1971) found the following relation for $h$ under unstable conditions:

$h\left(\frac{\left(z_{\mathrm{LAS}}-d\right)}{L_{\mathrm{MO}}}\right)=c_{\mathrm{T} 1}\left(1-c_{\mathrm{T} 2} \frac{\left(\mathrm{z}_{\mathrm{LAS}}-d\right)}{\mathrm{L}_{\mathrm{MO}}}\right)^{-2 / 3}$

where $c_{\mathrm{T} 1}$ and $c_{\mathrm{T} 2}$ are constants, given by De Bruin et al. (1993) as 4.9 and 9 .
Under stable conditions, Thiermann and Grassl (1992) proposed:

$h\left(\frac{\left(z_{\mathrm{LAS}}-d\right)}{\mathrm{L}_{\mathrm{MO}}}\right)=6.34\left(1+7 \frac{\mathrm{z}_{\mathrm{LAS}}-d}{\mathrm{~L}_{\mathrm{MO}}}+20\left(\frac{\mathrm{z}_{\mathrm{LAS}}-d}{\mathrm{~L}_{\mathrm{MO}}}\right)^{2}\right)^{1 / 3}$

$L_{\mathrm{MO}}$ is the Monin-Obhukov length $(\mathrm{m})$ given by:

$L_{\mathrm{MO}}=-\frac{\mathrm{T}_{\mathrm{a}} \mathrm{u}^{* 2}}{\mathrm{kgT}^{*}}$

with $k=0.41$ is the von Karman constant, $g=9.81 \mathrm{~m} \mathrm{~s}^{-2}$ (gravity) and $u^{*}\left(\mathrm{~m} \mathrm{~s}^{-1}\right)$ is the friction velocity:

$u^{*}=k u\left[\ln \left(\frac{\left(z_{\mathrm{LAS}}-d\right)}{z_{0}}\right)-\psi\left(\frac{\left(\mathrm{z}_{\mathrm{LAS}}-d\right)}{\mathrm{L}_{\mathrm{MO}}}\right)\right]^{-1}$

$u$ is the wind speed and $\psi$ is the integrated stability function defined for unstable conditions $\left(z / L_{\mathrm{MO}}<0\right)$ as (Panofsky and Dutton, 1984)

$\psi\left(\frac{\left(\mathrm{z}_{\mathrm{LAS}}-d\right)}{\mathrm{L}_{\mathrm{MO}}}\right)=2 \ln \left[\frac{1+x}{2}\right]+\ln \left[\frac{1+x^{2}}{2}\right]-2 \arctan (x)+\frac{\pi}{2}$

with

$x=\left(1-16 \frac{z_{\mathrm{LAS}}-d}{L_{\mathrm{MO}}}\right)^{1 / 4}$

$z_{0}$ is the roughness length. Knowing $u^{*}$ and $T^{*}$, the sensible heat flux $\mathrm{H}_{\text {LAS }}\left(\mathrm{W} \mathrm{m}^{-2}\right)$ can be calculated as:

$H_{\text {LAS }}=\rho C_{p} u^{*} T^{*}$

with $\rho\left(\mathrm{kg} \mathrm{m}^{-3}\right)$ and $\mathrm{c}_{\mathrm{p}}\left(\mathrm{kg}^{-1} \mathrm{~K}^{-1}\right)$ are the air density and heat capacity, respectively.

The latent heat flux from the LAS is obtained as the residual the energy balance as (Meijninger et al., 2002a):

$L_{\mathrm{v}} E_{\mathrm{LAS}}=R_{\mathrm{n}}-\mathrm{G}-\mathrm{H}_{\mathrm{LAS}}$

In this study, a footprint model proposed by Horst and Weil (1992, 1994) was applied to determine the source areas for turbulent fluxes from the EC and the LAS (see Appendix A). In the case of the LAS, one has to combine footprint function with the spatial weighting function $\mathrm{W}(\mathrm{x})$ of the LAS in order to calculate the source area.

\subsection{Proposed models to estimate available energy}

\subsubsection{Net radiation}

The net radiation quantifies the energy available for crop evapotranspiration, photosynthesis, and soil heating (Monteith and Unsworth, 1990). Several authors have related net radiation to solar radiation by means of empirical relationships (André and Viswanadham, 1983; Kowalik and Turner, 1983; Mermier and Seguin, 1976). Unfortunately, these relationships may be difficult to be generalized to all surface and atmospheric conditions. In this study, the following 
method for estimating net radiation at half-hourly time step from classical meteorological data is used. The net radiation is expressed as follows (Ortega-farias et al., 2000):

$R_{\mathrm{n}}=(1-\alpha) R_{\mathrm{g}}+\varepsilon_{\mathrm{S}} R_{\mathrm{a}}-R_{\mathrm{t}}$

where $\alpha$ is the surface albedo, $R_{\mathrm{g}}$ is the solar global radiation $\left(\mathrm{W} \mathrm{m}{ }^{-2}\right), \varepsilon_{\mathrm{S}}$ is the surface emissivity, $R_{\mathrm{a}}$ the atmospheric radiation which is emitted by air molecules $\left(\mathrm{W} \mathrm{m}^{-2}\right)$ and $R_{\mathrm{t}}$ is the terrestrial radiation which is emitted by the surface $\left(\mathrm{W} \mathrm{m}^{-2}\right)$. By using the Stefan-Boltzman equation (Monteith and Unsworth, 1990), $R_{\mathrm{a}}$ and $R_{\mathrm{t}}$ can be expressed as a function of air and surface temperatures, respectively. Then, Eq. (13) can be rewritten as:

$R_{\mathrm{n}}=(1-\alpha) R_{\mathrm{g}}+\varepsilon_{\mathrm{S}} \sigma\left(\varepsilon_{\mathrm{a}} \mathrm{T}_{\mathrm{a}}^{4}-\mathrm{T}_{\text {surf }}^{4}\right)$

with $\varepsilon_{\mathrm{a}}$ is the emissivity of the atmosphere, $\mathrm{T}_{\mathrm{a}}$ is the air temperature $(\mathrm{K}), \mathrm{T}_{\text {surf }}$ is the surface temperature $(\mathrm{K})$, and $\sigma$ is the Stefan-Boltzman constant $\left(5.67 \times 10^{-8} \mathrm{~W} \mathrm{~m}^{-2} \mathrm{~K}^{-4}\right)$. In this study, $T_{\text {surf }}$ was estimated from measured soil and canopy temperatures weighted by the fractional area of vegetation (Norman et al., 1995):

$\mathrm{T}_{\text {surf }} \approx\left[f_{\mathrm{c}} \mathrm{T}_{\mathrm{c}}^{4}+\left(1-f_{\mathrm{c}}\right) \mathrm{T}_{\mathrm{s}}^{4}\right]^{1 / 4}$

where $f_{c}$ is the cover fraction of olive trees.

Many authors have proposed empirical relationships which relate the atmospheric emissivity to the air temperature (Angstrom, 1918; Brunt, 1932; Idso, 1981). In what follows, we used the expression proposed by Brutsaert (1975) where $\varepsilon_{\mathrm{a}}$ is computed from air temperature and vapour pressure as:

$\varepsilon_{\mathrm{a}}=1.24\left(\frac{e_{\mathrm{a}}}{\mathrm{T}_{\mathrm{a}}}\right)^{1 / 7}$

where $e_{\mathrm{a}}$ is the air vapour pressure (hPa). Brutsaert (1975) pointed out that the 1.24 value for the proportionality coefficient, which was derived on an atmospheric radiative transfer basis, should vary according to variations in the type of atmosphere. Hatfield et al. (1983) and Olioso (1992) found that the original coefficient in the Brutsaert formula (1.24) led to an underestimation in calculated atmospheric radiation by $5 \%$.

\subsubsection{Soil heat flux}

Due to the complexity of surface cover and physical processes occurring in the soil, the soil heat flux is the most difficult scalar to measure accurately at the appropriate space-scale. Several authors have related this scalar to the net radiation (Stull, 1988; Villalobos et al., 2000). In this study, we used the simple formula proposed by Su et al. (2001):

$G=R_{\mathrm{n}}\left[\Gamma_{\mathrm{c}}+\left(1-f_{\mathrm{c}}\right)\left(\Gamma_{\mathrm{s}}-\Gamma_{\mathrm{c}}\right)\right]\left(\mathrm{Wm}^{-2}\right)$

in which they assume the ratio of soil heat flux to net radiation is $\Gamma_{\mathrm{C}}=0.05$ for full vegetation canopy (Monteith, 1973) and $\Gamma_{\mathrm{s}}=0.315$ for bare soil (Kustas and Daughtry, 1989).

\section{Experimental site and measurements}

\subsection{Site description}

289

The experiment was carried out between day of year (DOY) 323 (2002) and DOY 323 (2003) at the 275 ha Agdal olive orchard which is located to the southeast of the city of Marrakech, Morocco $\left(31^{\circ} 36^{\prime} \mathrm{N}, \mathrm{W} 007^{\circ} 58^{\prime}\right)$. Fig. 1 displays the area of interest on a very high spatial resolution image acquired by the Quickbird satellite (0.62 and $2.4 \mathrm{~m}$ in panchromatic and multispectral, respectively). The climate is typically semi arid Mediterranean; precipitation falls mainly during winter and spring, from the beginning of November until the end of April, with an average ranging from 192 to $253 \mathrm{~mm}$ per year. The atmosphere is very dry with an average humidity of $56 \%$ and the evaporative demand is very high (1600 $\mathrm{mm}$ per year), greatly exceeding the annual rainfall.

The experiment was set up in the southern area of the Agdal orchard, of about $700 \mathrm{~m} \times 800 \mathrm{~m}$, surrounded by fields of orange and olive trees (Fig. 1). The average height of the olive trees is $6 \mathrm{~m}$ with an average coverage that reaches approximately $55 \%$. Two water basins are used for irrigation. Water is diverted manually to every tree through a network of ditches, each tree is surrounded by a small earthen levy that retains the irrigation water, allowing application of irrigation water to every tree. The amount of water used during each irrigation event was about $80 \mathrm{~mm}$. Irrigation starts on the southern border of the field, and, depending on available manpower, progresses towards the northern border of the site in approximately 12 days.

\subsection{Micrometeorological and flux measurements}

The field was equipped with a set of standard meteorological instruments to measure wind speed and direction (with a

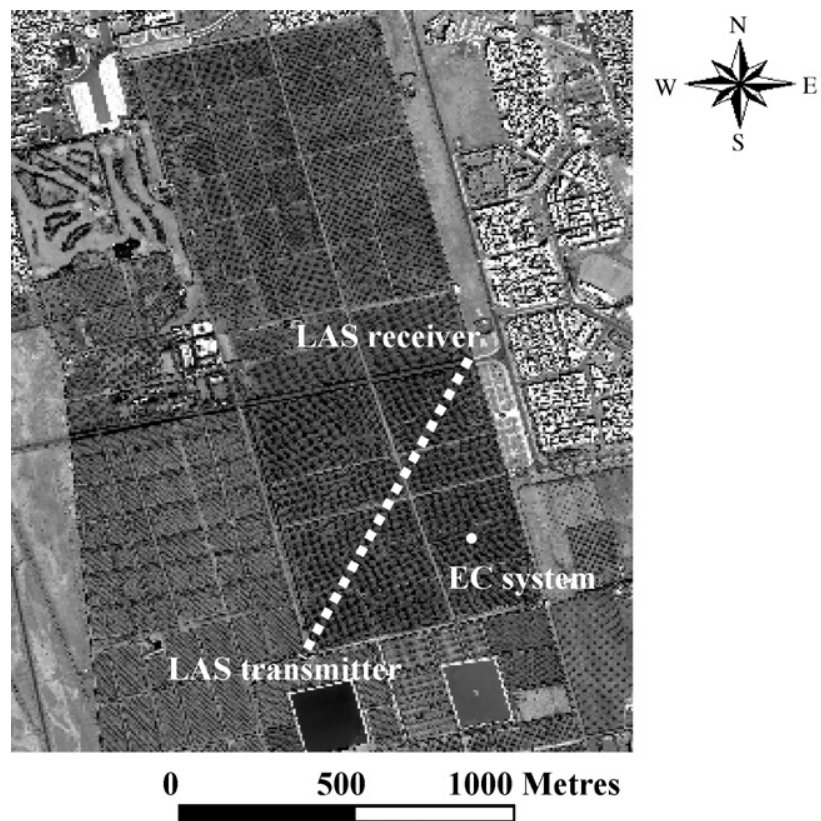

Fig. 1 - Overview of the study site (Quickbird image). The white dotted line represents the LAS path, and the location of EC system is also presented. 
Young Wp200 anemometer), air temperature and humidity (with a vaisala HMP45AC probe) at $9 \mathrm{~m}$ above the ground. The four components of the net radiation were measured using a CNR1 radiometer (Kipp \& Zonen), i.e. independant estimates incoming and outgoing solar and far-infrared radiation. The CNR1 was located in a place (at $8.5 \mathrm{~m}$ ) that is representative of the vegetation and soil. Radiative soil and vegetation temperatures were measured using 2 IRTS-P's (Apogee). The soil heat flux density was measured using heat flux plates (HFT3-L, Campbell Scientific Ltd.) at three locations with contrasting amounts of radiation reaching the soil. The measurement depth was $1 \mathrm{~cm}$. The plates were placed: one below the tree near the trunk in order not to be exposed to direct solar radiation; one was exposed directly to solar radiation, the last one in an intermediate position. An average of these three measurements was made to obtain a representative value. Soil temperature was recorded at two locations at a depth of $0.05 \mathrm{~m}$ (temperature probe 108). Soil moisture was measured at different depths $(0.05,0.1,0.2,0.3$ and $0.4 \mathrm{~m})$ using 5 CS616 water content reflectometers (Campbell Scientific Ltd.). Measurements were sampled at $1 \mathrm{~Hz}$, averaged, and then stored at 30 min intervals on CR10X dataloggers.

An EC system was installed to provide continuous measurements of vertical fluxes of heat, water vapour and carbon dioxide $\left(\mathrm{CO}_{2}\right)$ at $9.2 \mathrm{~m}$ (see Fig. 1). During the first three months the EC system consisted of a 3D sonic anemometer (CSAT3, Campbell Scientific Ltd.) which measured the fluctuations in the wind velocity components and temperature, and an open-path infrared gas analyser (LICOR-7500, Campbell Scientific Ltd.) that measured concentration of water vapour and carbon dioxide. Raw data were sampled at a rate of $20 \mathrm{~Hz}$ and were recorded using a CR23X dataloggers (Campbell Scientific Ltd.) which were connected to portable computer to enable storage of large raw data files. After the first three months of the experiment, the LICOR-7500 IRGA was replaced by a Krypton hygrometer (KH20, Campbell Scientific Ltd.), and the datalogging system was replaced with a CR5000 datalogger (Campbell Scientific Ltd.), equipped with a 1 Gb PCMCIA-card for the storage of large raw data files. The half-hourly fluxes were later calculated off-line after performing planar fit corrections (Wilczak et al., 2001), correcting the sonic temperature for the presence of humidity (Schotanus et al., 1983), frequency response corrections for slow apparatus and path length integration (Moore, 1986), the inclusion of the mean vertical velocity according to Webb et al. (1980) and oxygen correction for the Krypton hygrometer, which is sensitive to $\mathrm{O}_{2}$ (Van Dijk et al., 2003). For the data processing, use was made of the eddy covariance processing software 'ECpack', developed by the Meteorology and Air Quality Group, Wageningen University. This software is available for download at http://www.met.wau.nl/.

In order to ascertain that the height of the EC was adequate and fulfils the conditions required for turbulent fluxes measurements (i.e. the constant-flux layer), one can study the behaviour of the temperature structure parameter $\left(C_{\text {TEC }}^{2}\right)$, the temperature scale $\left(\mathrm{T}_{\mathrm{EC}}^{*}\right)$ and the Monin-Obhukov length $L_{\text {MON EC }}$ derived from the EC according to MOST. For this purpose, observed values of $C_{\mathrm{TEC}}^{2}\left(\mathrm{z}_{\mathrm{EC}}-d\right)^{2 / 3} / \mathrm{T}_{\mathrm{EC}}^{* 2}$ have been plotted against observed values of $\left(\mathrm{z}_{\mathrm{EC}}-d\right) / \mathrm{L}_{\mathrm{MONEC}}$ in Fig. 2, together with the scaling curve (Eq. (6)). The measurements

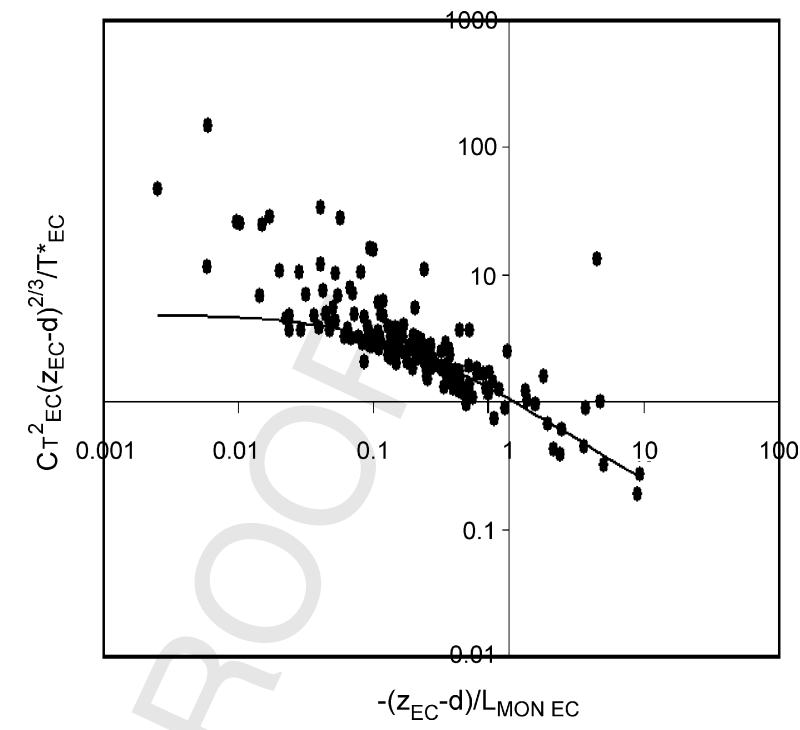

Fig. 2 - Observed values of $C_{\mathrm{TEC}}^{2}\left(\mathrm{z}_{\mathrm{EC}}-d\right)^{2 / 3} / \mathrm{T}_{\mathrm{EC}}^{* 2}$ plotted against observed $\left(z_{\mathrm{EC}}-d\right) / \mathrm{L}_{\mathrm{EC}}$, all data were derived from the EC system. Solid line represents the scaling giving by De Bruin et al. (1993): 4.9(1-9( $\left.\left.\mathrm{z}_{\mathrm{EC}}-d\right) / \mathrm{L}_{\mathrm{EC}}\right)^{-2 / 3}$.

follow the shape of the theoretical scaling given by De Bruin et al. (1993). Therefore, it can be conclude that the measurements were taken in the constant-flux layer.

Additionally, two identical LAS were used in this experiment, the first one (denoted LAS $_{1}$ ) was operated from the beginning of the experiment until DOY 12 (2003) and was then replaced with the second one (denoted $\mathrm{LAS}_{2}$ ). Both of them were built by the Meteorology and Air Quality Group (Wageningen Agriculture University, the Netherlands). These instruments were made according the basic design described in Ochs and Wilson (1993). They have an aperture size of $0.15 \mathrm{~m}$ and the wavelength of the light beam emitted by the transmitter is $940 \mathrm{~nm}$. At the receiver, $C_{n}^{2}$ was sampled at $1 \mathrm{~Hz}$

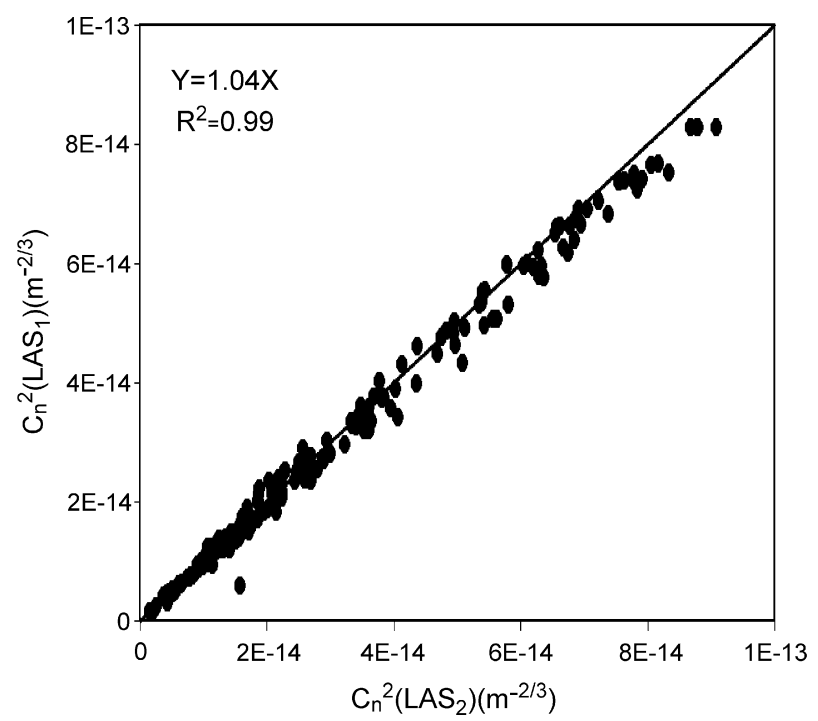

Fig. 3 - Inter-comparison between the two scintillometers referred as $\mathrm{LAS}_{1}$ and $\mathrm{LAS}_{2}$ used in the experiment. 
and averaged over $1 \mathrm{~min}$ time steps by a CR510 datalogger. The LAS were installed perpendicularly to the dominant wind direction with a path length of $1 \mathrm{~km}$. The transmitter was mounted on a tripod installed on a roof, located on the southwest corner of the field, while the receiver was mounted on a $15 \mathrm{~m}$ high tower that was positioned next to the road (see Fig. 1). The path of the scintillometer was chosen so that the saturation effects are expected to be small (Kohsiek et al., 2006).

In order to be more confident in the consistency in the measurements made by both LAS, an inter-comparison of the two LAS was performed between DOY 284 (2002) and 288 (2003). To avoid possible interference between the two signals, the transmitter and receiver were alternated. They were deployed at the same height. The linear regression forced through the origin yielded $\left(\mathrm{m}^{-2 / 3}\right): \mathrm{C}_{n}^{2}\left(\mathrm{LAS}_{1}\right)=1.04 C_{n}^{2}\left(\mathrm{LAS}_{2}\right)$, $R^{2}=0.99$. This means that the agreement is excellent with $4 \%$ difference (Fig. 3). This small difference lies within acceptable instrumental error.

\section{Results and discussions}

In this paragraph we first analysed the closure of the energy balance. Then the measured and simulated $\left(R_{n}-G\right)$ components were compared, as well as the sensible heat flux measured by EC $\left(H_{E C}\right)$ and that derived from the LAS $\left(H_{L A S}\right)$. After that, the feasibility of deriving the latent heat flux from the LAS with the estimated values of the available energy $\left(R_{n}-G\right)$ was checked, so that $L_{v} E$ can be derived at large scale with a minimum number of instruments in the fields.

\subsection{Energy balance closure}

The energy balance closure is an important indicator of the performance of an EC system. By ignoring the term of canopy

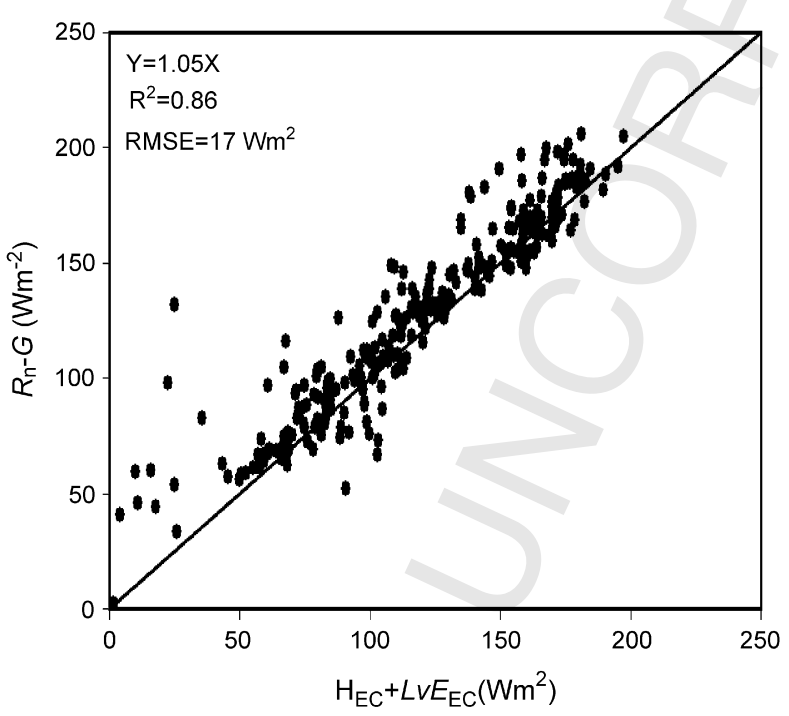

Fig. 4 - Assessment of energy balance closure. Daily average fluxes of net radiation $\left(R_{n}\right)$ minus the soil heat flux $(G)$ are compared against the sums of sensible $\left(H_{\mathrm{EC}}\right)$ and latent heat $\left(\mathrm{L}_{\mathrm{v}} \mathrm{E}_{\mathrm{EC}}\right)$ measured by the eddy correlation system.

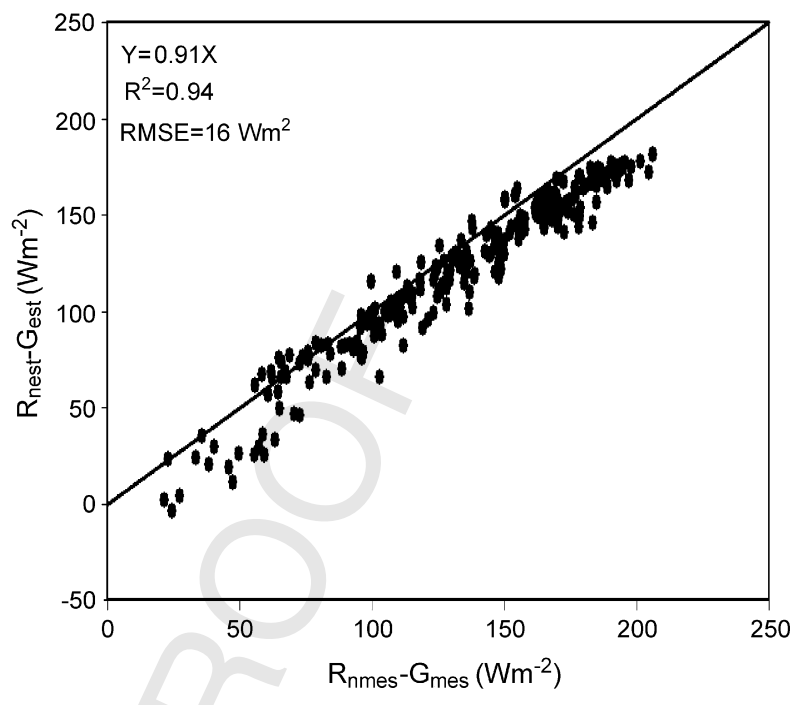

Fig. 5 - Comparison between daily estimated ( $\left.R_{\text {nest }}-G_{\text {est }}\right)$ and observed ( $R_{\text {nmes }}-G_{\text {mes }}$ ) available energy.

heat storage at daily time scale (Testi et al., 2004; Baldocchi et al., 2004) and assuming the principle of conservation of energy, the energy balance closure is defined as $R_{\mathrm{n}}-H_{\mathrm{EC}}-L_{\mathrm{v}} E_{\mathrm{EC}}-G$ and should be close to zero $\left(L_{\mathrm{v}} E_{\mathrm{EC}}\right.$ is the latent heat flux derived from the EC). In this study all daily values were calculated by averaging up the half-hourly values. Fig. 4 presents a cross plot between measured $\left(R_{n}-G\right)$ and the sum of the turbulent fluxes $\left(H_{E C}+L_{V} E_{E C}\right)$ for daily time scale. A linear regression yields: $R_{n}-G=1.05\left(H_{\mathrm{EC}}+L_{\mathrm{v}} E_{\mathrm{EC}}\right)$ and $R^{2}=0.86$, with $\mathrm{RMSE}=17 \mathrm{~W} \mathrm{~m}^{-2}$ (the equation used to calculate RMSE is presented in Appendix B). The difference in terms of the sources areas of the different instruments has the biggest impact on the closure of the energy balance especially over sparsely vegetated surfaces. The source area sampled by eddy covariance is much larger than that of net radiation and soil heat flux and it can change rapidly depending on wind speed and direction and on surface conditions. However, comparatively to what has been reported in the literature (Testi et al., 2004; Baldocchi et al., 2004; Twine et al., 2000), the closure can be considered as fairly good.

\subsection{Estimating available energy}

The net radiation is derived from Eq. (14) using an albedo value of 0.11 (annual averaged measured with CNR1), a surface emissivity of 0.98 (Jones et al., 2003), and the atmospheric radiation is computed from air temperature and vapour pressure using Brutsaert's formula with a correction factor taking into account the $5 \%$ underestimation shown by different authors (Hatfield et al., 1983; Olioso, 1992; Ortegafarias et al., 2000). The soil heat flux was estimated using Eq. (17). Due to power supply problems at the beginning of the experiment, some data were missing, we therefore used 270 days of data.

The comparison between daily observed and estimated available energy is presented in Fig. 5. A regression analysis yields $\left(\mathrm{W} \mathrm{m}^{-2}\right): R_{\text {nest }}-G_{\text {est }}=0.91\left(R_{\text {nmes }}-G_{\text {mes }}\right), R^{2}=0.94$, and $\mathrm{RMSE}=16 \mathrm{~W} \mathrm{~m}^{-2}$. The subscripts est and mes referred to 


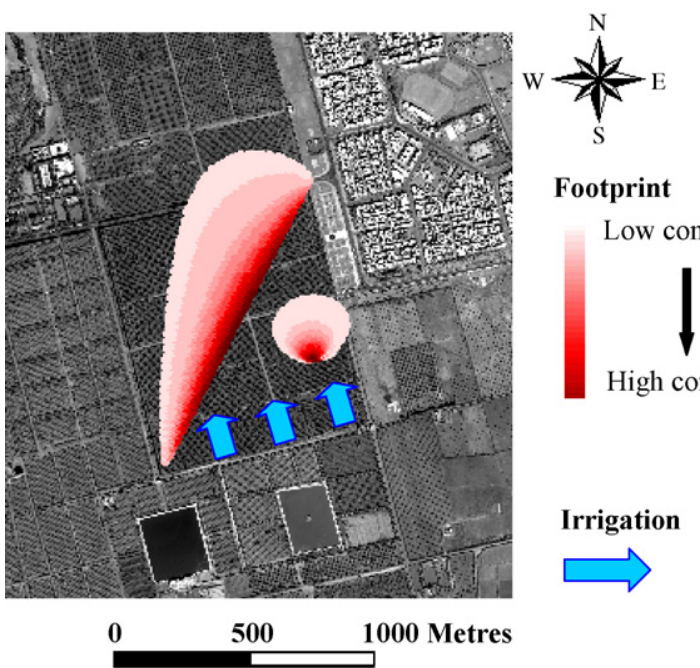

Fig. 6 - Footprints of the LAS and EC system (corresponding to approximately $95 \%$ of the sensible heat flux) are shown in red and the irrigation schedule in blue.

estimated and measured values, respectively. It can be seen that the simple model used to estimate the available energy works fairly well over tall and sparse vegetation (an underestimation of $9 \%$ ). It must be noted that the use of the Brutsaert's formula which was established for clear sky conditions only, may create an important scatter for low radiation values. To overcome this difficulty, a comparison between the $R_{\text {nmes }}$ and $R_{\text {nest }}$ using the measured and the estimated atmospheric radiation was made (not shown). A regression analysis for both comparisons yields almost the same slope $(\approx 0.96)$, but the $R^{2}$ and RMSE differed. The $R^{2}$ and RMSE were 1 and $5 \mathrm{~W} \mathrm{~m}^{-2}$, and 0.95 and $12 \mathrm{~W} \mathrm{~m}^{-2}$ for measured and estimated atmospheric radiation, respectively.

\subsection{Sensible and latent heat fluxes}

To assess the accuracy of the LAS, a comparison of the daily sensible heat fluxes derived from the LAS and those measured from the EC system was made. The days with missing data in LAS and EC measurements were not taken into account. Missing data was mostly due to rainfall and very strong wind associated with storms which disturbed the alignment of the LAS (about $12 \%$ of the data).

During this study, the site changes from being almost homogeneous under dry conditions or following rain events to very heterogeneous during the irrigation. The irrigation method creates a large difference in terms of soil moisture which leads to a large difference in the characteristics of the source area sampled by the LAS and by EC, respectively. In Fig. 6, the footprints of the LAS and EC (corresponding to approximately $95 \%$ of the sensible heat flux) for the prevailing wind direction are presented, together with the orientation of irrigation. It can be seen that during the irrigation the small source area of the EC will be irrigated much sooner than the large area of the LAS. Consequently, the EC source area started to dry out before the entire source area of the LAS is irrigated. Fig. $7 \mathrm{a}$ and $\mathrm{b}$, present comparisons between $\mathrm{H}_{\mathrm{LAS}}$ and $\mathrm{H}_{\mathrm{EC}}$ over
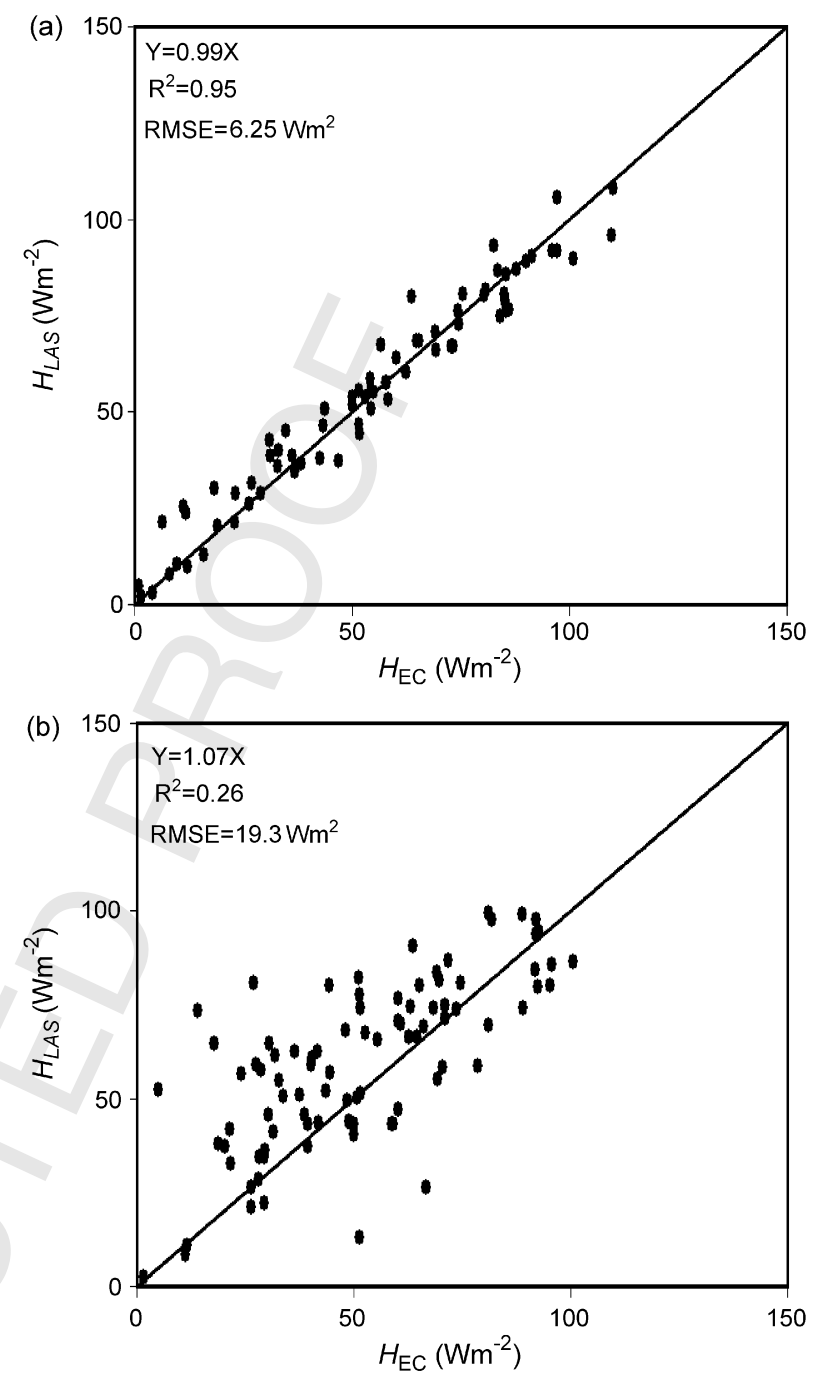

Fig. 7 - (a) Comparison between the daily averaged LAS and EC sensible heat fluxes, $H_{\text {LAS }}$ and $H_{E C}$, respectively, during homogenous conditions (dry conditions and days following the rain events). (b) Comparison between the daily averaged LAS and EC sensible heat fluxes, $H_{\text {LAS }}$ and $H_{\mathrm{EC}}$, respectively, during heterogeneous conditions (periods of irrigation events).

homogeneous and heterogeneous conditions, respectively. The correlation between $\mathrm{H}_{\mathrm{LAS}}$ and $\mathrm{H}_{\mathrm{EC}}$ during the irrigation was very poor $\left(R^{2}=0.26\right.$, RMSE $\left.=19.3 \mathrm{~W} \mathrm{~m}^{-2}\right)$, this disagreement was expected due to the irrigation method used, which causes a large heterogeneity in soil humidity of the sources area of the LAS and EC, which in turn affects the sensible heat flux. In contrast, the correlation was very good $\left(R^{2}=0.95\right.$, $\mathrm{RMSE}=6.25 \mathrm{~W} \mathrm{~m}^{-2}$ ) during homogenous conditions (dry conditions and days following the rain events). Examining the comparison during the entire year (Fig. 8), yields a satisfactory agreement $\left(R^{2}=0.72\right.$, RMSE $\left.=13.3 \mathrm{~W} \mathrm{~m}^{-2}\right)$. It can be therefore concluded that the effect induced by the irrigation method is compensated when comparison is made during the entire season. This result is of great interest since it indicates that the LAS can be effectively used to accurately estimate spatially 


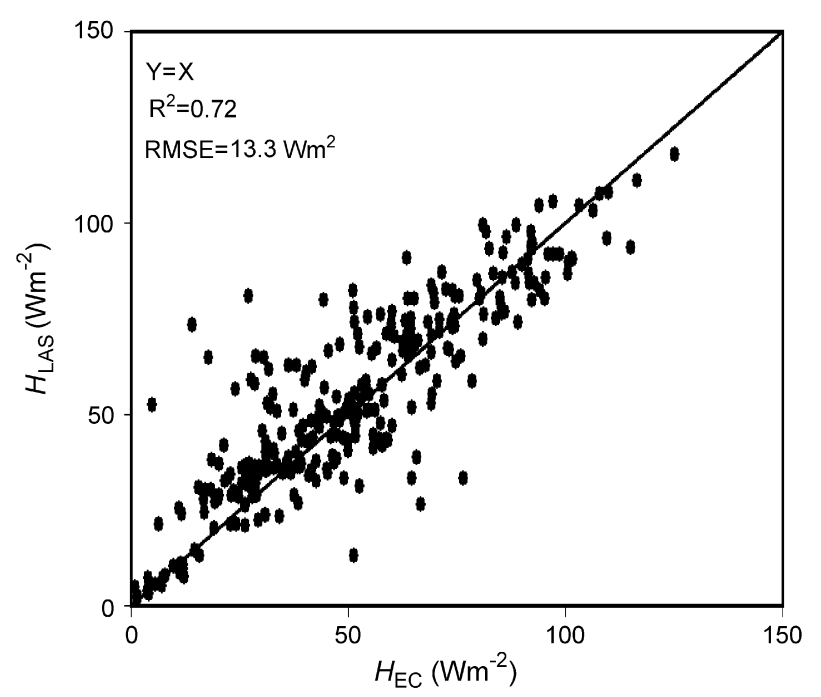

Fig. 8 - Comparison between the daily averaged LAS and EC sensible heat fluxes, $H_{\mathrm{LAS}}$ and $\mathrm{H}_{\mathrm{EC}}$, respectively, during the entire year. averaged sensible heat flux despite the heterogeneity induced by the irrigation method.

A comparison between the daily latent heat flux from the LAS $\left(L_{\mathrm{v}} E_{\mathrm{LAS}}\right)$ calculated as $L_{\mathrm{v}} E_{\mathrm{LAS}}=R_{\text {nest }}-G_{\text {est }}-H_{\mathrm{LAS}}$ and the latent heat flux from EC $\left(L_{V} E_{E C}\right)$ is shown in Fig. 9. The regression analysis gives: $L_{\mathrm{V}} E_{\mathrm{LAS}}=0.86 L_{\mathrm{V}} E_{\mathrm{EC}}, R^{2}=0.72$ and $\mathrm{RMSE}=18.25 \mathrm{~W} \mathrm{~m}^{-2}$. Such discrepancy can be explained by the combination of several factors. First, the error associated with the closure of the measured energy balance is translated into an error in the simulated $L_{\mathrm{V}} E_{\mathrm{LAS}}$. Second, since the scintillometer-based $L_{V} E_{L A S}$ is obtained as the residual term of the energy balance, any difference between measured and simulated available energy is directly

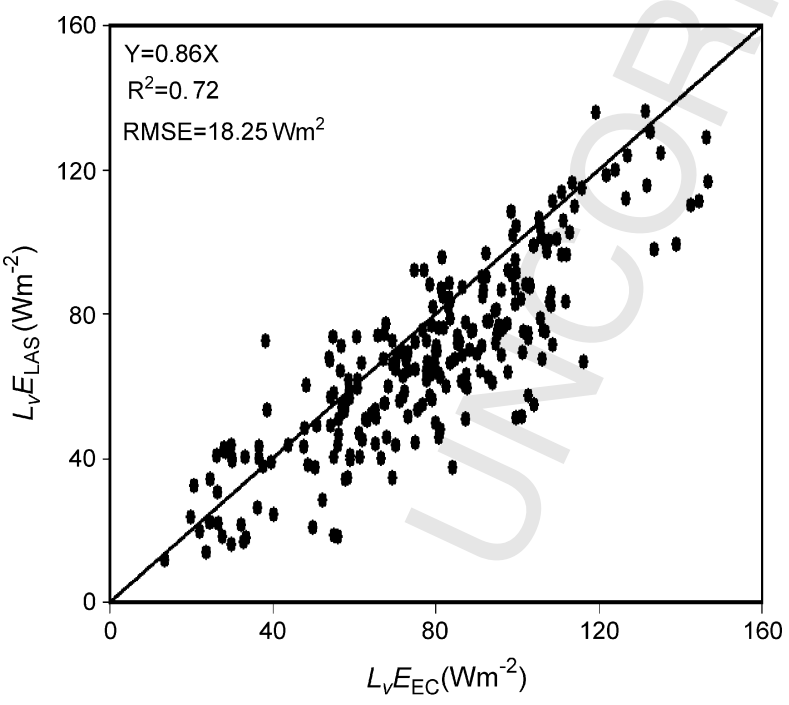

Fig. 9 - Comparison between daily observed (derived from EC system $L_{\mathrm{v}} E_{\mathrm{EC}}$ ) and simulated evapotranspiration (derived from the LAS using the estimated available energy, $\left.L_{v} E_{L A S}\right)$.

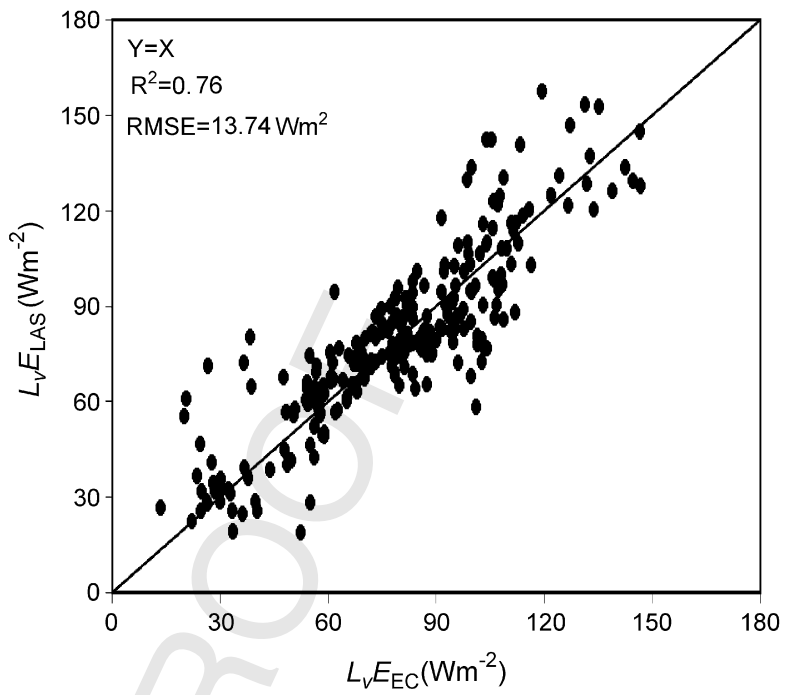

Fig. 10 - Comparison between daily observed (derived from EC system $L_{\mathrm{v}} E_{\mathrm{EC}}$ ) and simulated evapotranspiration (derived from the LAS using the measured available energy, $\left.L_{v} E_{L A S}\right)$.

translated into error in the simulated $L_{\mathrm{v}} E_{\mathrm{LAS}}$. In this regard, comparison between the $L_{\mathrm{v}} E_{\mathrm{LAS}}$ simulated using the measured available energy values (Fig. 10) and the $L_{\mathrm{v}} E_{\mathrm{EC}}$ yields to $L_{\mathrm{V}} E_{\mathrm{LAS}}=0.96 \mathrm{~L}_{\mathrm{V}} E_{\mathrm{EC}}, R^{2}=0.74$ with $\mathrm{RMSE}=14 \mathrm{~W} \mathrm{~m}^{-2}$. More importantly, the impact of the difference in the footprint of the LAS and EC which was very important during the irrigation events greatly influences the correspondence between observed and simulated fluxes. Although a moderate discrepancy is observed, the correspondence between measured and simulated $L_{v} E$ is deemed acceptable. Therefore, one can conclude that combining LAS measurements with estimates of available energy is a very effective and operational tool for seasonal crop water consumption assessment at a scale relevant to the managers (i.e. the irrigation district).

\subsection{Irrigation efficiency assessment}

In this paragraph, we investigate the efficiency of the irrigation practices over the study site which is representative of the practices in the region. To achieve this, crop water requirements deduced from the FAO-56 method (FAO-56 paper, Allen et al., 1998) were compared to the LAS-based estimates of $\mathrm{ET}_{\mathrm{LAS}}$ and the sum of the rainfall and irrigation.

During the experiment, the total irrigation applied by the farmer was about $800 \mathrm{~mm}$ over 10 irrigation cycles. Total precipitation $(P)$ during the experiment reached $354 \mathrm{~mm}$, which is much higher than the annual average of $240 \mathrm{~mm}$. The yearly estimated evapotranspiration $\left(\mathrm{ET}_{\mathrm{LAS}}\right)$ derived from the LAS was calculated by summing up the daily values. The result in terms of yearly estimates of ET using our approach (ET $\mathrm{LAS}_{\text {LA }}$ ) was about $860 \mathrm{~mm}$.

In order to compare this value against that suggested by the $\mathrm{FAO}$, the crop water requirement $\left(\mathrm{ET}_{\mathrm{c}}\right)$ was calculated following the standard procedure of the FAO (FAO-56 paper; Allen et al., 1998). $\mathrm{ET}_{\mathrm{c}}$ is computed by multiplying reference 


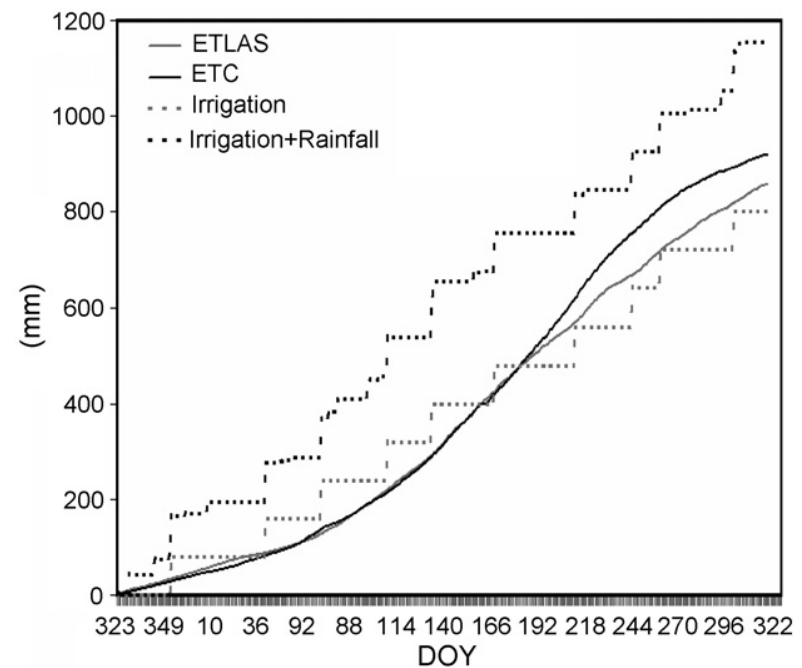

Fig. 11 - Accumulated crop evapotranspiration derived from FOA-56 $\left(\mathrm{ET}_{\mathrm{c}}\right)$, Evapotranspiration derived from the LAS (ET $\left.\mathrm{LAS}_{\mathrm{L}}\right)$, irrigation applied by the farmer and sum of irrigation and rainfall.

evapotranspiration $\left(\mathrm{ET}_{\mathrm{O}}\right.$ ) by a crop coefficient $\mathrm{K}_{\mathrm{c}}$. The mean value of $K_{\mathrm{C}}$ for olive orchard under environmental conditions is 0.68 (Er-Raki et al., 2006). The yearly simulated $\mathrm{ET}_{\mathrm{c}}$ during our experiment was $920 \mathrm{~mm}$. The accumulated $\mathrm{ET}_{\mathrm{LAS}}$ and $\mathrm{ET}_{\mathrm{C}}$ for olive season are shown in Fig. 11. By analyzing this figure, the accumulated $\mathrm{ET}_{\mathrm{LAS}}$ and $\mathrm{ET}_{\mathrm{c}}$ curves are close over the period DOY 323 to DOY 190. For the remaining days, $\mathrm{ET}_{\mathrm{C}}$ was higher than $\mathrm{ET}_{\mathrm{LAs}}$. This is due to the stress induced by irrigation delay. It can be noticed also in this figure, that although the sum of irrigation and rainfall was greater than $\mathrm{ET}_{\mathrm{C}}$, one stress event occurred (from DOY 190). Such behaviour can be explained by inadequate distribution of irrigation. In fact, the farmer irrigated just after the recorded rainfall (four irrigations were applied in this case: DOY 353 (2002), 109 (2003), 169 (2003) and 303 (2003)). Some of those irrigations should have been delayed (169 (2003), 309 (2003), 109 (2003)) and the first irrigation (353 (2002)) was unnecessary because it had rained for a long period beforehand. In addition, an important amount of water was lost by the flood irrigation technique. This quantity was lost by deep percolation and runoff and is noted $\Delta P$. In order to quantify this term, the water balance equation of the FAO method on a yearly basis (Allen et al., 1998) was applied. In this study we ignored the variation in the water storage in the study area, because the initial conditions were similar to the conditions at the end of the experiment. So $\Delta \mathrm{P}$ approached the sum of the total precipitation and irrigation minus the cumulative of the $\mathrm{ET}_{\text {LAS }}$. The yearly $\Delta \mathrm{P}$ obtained was around $295 \mathrm{~mm}$ considering the irrigation's quantity applied by the farmer, so it represents about $37 \%$ of the total applied irrigation. Another study was done over the same field by Williams et al. (2003) and showed that after the irrigation the soil evaporation represents about $14-28 \%$ of the total evapotranspiration. The result revealed that the farmer applied a large amount of water and the irrigation system was not appropriate for the orchard in the Haouz plain conditions.

\section{Conclusion}

The purpose of this investigation was to identify whether the large aperture scintillometer combined with a simple available energy model could be used to monitor the water consumption in difficult environment conditions (tall vegetation, irrigation method which has an irregular pattern in space and time, and variable soil characteristics). An experiment was conducted over the irrigated oliveyard of Agdal which is located in Marrakech (Morocco). An eddy covariance (local scale measurements) and LAS (large scale measurements) were installed above the olive trees.

The daily sensible heat fluxes derived from the LAS agreed reasonably well with those derived from the EC during homogenous conditions (dry conditions and days following the rain events). This result confirms that the LAS works well over tall and sparse vegetation. During the irrigation events (flooding irrigation), the comparison showed a large scatter between the two methods due to the large difference in the sources area of the LAS and EC created by the irrigation method.

Consequently, the comparison between the latent heat flux derived from the LAS and that measured by EC yields an acceptable agreement with an underestimation of $14 \%$ and a large scatter $\left(R^{2}=0.72\right.$ and $\left.R M S E=18.25 \mathrm{~W} \mathrm{~m}^{-2}\right)$. This difference was related to the poor closure of the energy balance based on EC turbulent fluxes estimates, the different characteristics between the source areas of the LAS and EC (due to the irrigation method which created a large heterogeneity in soil moisture), and the use of Brutsaert's formula to compute downward longwave radiation. It is concluded that the use of estimate available energy which can be derived from the satellite image, the scintillometer is a potentially useful tool to obtain the latent heat flux at large scale even over complex surfaces. Therefore, this device provides a great potential for practical application of remote sensing approaches to basin scale water balance studies.

In addition, the study revealed that the method of irrigation applied by the farmer was not appropriate for the orchard conditions, because a large quantity of water is ( $\approx 295 \mathrm{~mm})$ lost by deep percolation and overflow ( $\approx 37 \%$ of total irrigation). One can therefore conclude that the irrigation is not efficient, because the irrigation monitoring is done by visually observing the physical conditions of the plant which is not sufficient to manage the irrigation. As a result, it would be advisable to improve the irrigation management and to recommend to the farmer to follow a more technical irrigation scheduling criteria such as, that is by taking into account the actual soil type, slope, length of water run, flow rates, and weather forecast.

\section{Acknowledgements}

This research was situated within the framework of SUDMED project and E.U. funded IRRIMED (http://www.irrimed.org) project. A part of this study has been supported by the Dutch Technology Foundation (STW project WMO 4133), the research council of the Netherlands Organization of Scientific Research (NWO). During a few months in 2002 the third author (J.C.B. Hoedjes) was employed by Wageningen University on STW 
funding. We are grateful to the Institut de Recherche pour le Dévellopement (IRD). We are indebted to the director and staff of the Agdal olive orchard for access and use of the field site and for assistance with irrigation scheduling and security. Oscar K. Hartogensis is acknowledged for his assistance with setting up the instruments at Agdal in September 2002, and for his advise for raw data processing. In addition, he is thanked for his valuable comments on this manuscript. The authors acknowledge the helpful comments of the three anonymous referees.

\section{Appendix A}

The contributing surface to scalar flux measurement from the EC and the LAS, called the source area (SA), was calculated using the analytical footprint model proposed by Horst and Weil $(1992,1994)$. The footprint function $f$, or the contribution per unit surface flux of each unit element of the upwind surface area to a measured vertical flux, relates to the vertical flux measured at height $z_{m}, F\left(x, y, z_{m}\right)$, to the spatial distribution of surface fluxes, $F(x, y, z=0) \equiv F 0(x, y)$, i.e.,

$$
F\left(x, y, z_{m}\right)=\int_{-\infty}^{\infty} \int_{\infty}^{x} F_{0}\left(x^{\prime}, y^{\prime}\right) f\left(x-x^{\prime}, y-y^{\prime}, z_{m}\right) d x^{\prime} d y^{\prime}
$$

(Horst and Weil, 1994). Where $x$ and $y$, respectively, are the upwind and crosswind distances $(\mathrm{m})$ from the point where the measurements are taken. The source area arises from the integration of the footprint function. In this study we calculated the crosswind-integrated footprint function using the model of Horst and Weil (1994):

$\bar{f}^{y}\left(x, z_{m}\right) \cong \frac{d \bar{z}}{d x} \frac{z_{m}}{\bar{z}^{2}} \frac{\bar{u}\left(z_{m}\right)}{\bar{u}(c \bar{z})} A \exp \left[-\left(\frac{z_{m}}{b \bar{z}}\right)^{r}\right]$

where $\mathrm{z}$ is the mean plume height for diffusion from a surface source and $u(z)$ the mean wind speed profile. The variables $A, b$ and $c$ are gamma functions of shape parameter $r$. We have assumed that the violation of the MOST is small (Meijninger et al., 2002b). In the case of the LAS, one has to combine $f$ with the spatial weighting function $W(x)$ of the LAS in order to calculate the source area.

\section{Appendix B}

The root mean square error (RMSE), which measures the variation of predicted values around observed ones, is calculated as follows:

RMSE $=\sqrt{\frac{1}{n} \sum_{i=1}^{n}\left(y_{i \text { sim }}-y_{\text {iobs }}\right)^{2}}$

where $y_{i \text { sim }}$ and $y_{i \text { obs }}$ are the values of simulated and observed variables, respectively, and $n$ is the number of observations.
R E F E R E N C E S

Allen, R.G., Pereira, L.S., Raes, D., Smith, M., 1998. Crop Evapotranspiration-Guidelines for Computing Crop Water Requirements, Irrigation and Drain, Paper No. 56. FAO, Rome, Italy, $300 \mathrm{pp}$.

Andreas, E.L., 1989. Two-wavelength method of measuring path-averaged turbulent surface heat fluxes. J. Atmos. Oceanic Technol. 6, 280-292.

André, R.G.B., Viswanadham, Y., 1983. Radiation balance of soybeans grown in Brazil. Agric. For. Meteorol. 30, 157-173.

Angstrom, A., 1918. A study of the net radiation of the atmosphere. Smithson. Inst. Coll. 65, 159-161.

Baldocchi, D.D., Xu, L., Kiang, N., 2004. How plant functionaltype, weather, seasonal drought, and soil physical properties alter water and energy fluxes of an oak-grass savanna and an annual grassland. Agric. For. Meteorol. 123, 13-39.

Beyrich, F., Leps, J.P., Mauder, M., Bange, J., Foken, T., Huneke, S., Lohse, H., Ludi, A., Meijninger, W.M.L., Mironov, D., Weisensee, U., Zittel, P., 2006. Area averaged surface fluxes over the Litfass region based on eddy-covariance measurements. Boundary-Layer Meteorol. 121, 33-65.

Beyrich, F., Richter, S.H., Weisensee, U., Koshsiek, W., Bosveld, F., Lohse, H., De Bruin, H.A.R., Hartogensis, O.K., Bange, J., Vogt, R., 2000. The LITFASS-98 experiment: fluxes over a heterogeneous land surface. In: 14th Symposium on Boundary Layer and Turbulence, 7-11August, 2000, American Meteorological Society, Aspen, CO, pp. 9-10.

Brunt, D., 1932. Notes on radiation in the atmosphere. Q. J. R. Meteorol. Res. 58, 389-418.

Brutsaert, W., 1975. On a derivable formula for long-wave radiation from clear skies. Water Resour. Res. 11, 742-744.

Chehbouni, A., Escadafal, R., Dedieu, G., Errouane, S., Boulet, G., Duchemin, B., Mougenot, B., Simonneaux, V., Seghieri, J., Timouk, F., 2003. A multidisciplinary program for assessing the sustainability of water resources in semi-arid basin in Morocco: SUDMED. In: Proceedings of the EGS-AGU-EUG joint Assembly,, 6-11 April, Nice, France.

Chehbouni, A., Escadafal, R., Boulet, G., Duchemin, B., Dedieu, G., Hannich, L., et al., 2004. Integrated modelling and remote sensing approach for sustainable management of water resources in Tensift region (SudMed): preliminary results, current status and new challenges. In: Integrated Water Resources Research and Development southeastern Morocco, International Conference, 1-2 April 2004, Ouarzazate, Moroccco.

Chehbouni, A., Watts, C., Lagouarde, J.P., Kerr, Y.H., Rodriguez, J.C., Bonnnefond, J.M., Santiago, F., Dedieu, G., Goodrich, D.C., Unkrich, C., 2000. Estimation of heat fluxes and momentum fluxes over complex terrain using a large aperture scintillometer. Agric. For. Meteorol. 105, 215-226.

Chehbouni, A., Kerr, Y.H., Watts, C., Hartogensis, O., Goodrich, D.C., Scott, R., Schieldge, J., Lee, K., Shuttleworth, W.J., Dedieu, G., De Bruin, H.A.R., 1999. Estimation of areaaverage sensible heat flux using a large aperture scintillometer. Water Resour. Res. 35, 2505-2512.

De Bruin, H.A.R., Kohsiek, W., Van den Hurk, B.J.J.M., 1993. A verification of some methods to determine the fluxes of momentum, sensible heat and water vapour using standard deviation and structure parameter of scalar meteorological quantities. Boundary-Layer Meteorol. 76, 25-40.

Er-Raki, S., Chehbouni, G., Guemouria, N., Ezzahar, J., Hadria, R., Duchemin, B., Boulet, G., Chehbouni, A., 2006. Developing crop coefficients for olive, wheat and orange growing in semi arid region (Marrakech, Morocco). Integrated Water 
Resources Management and Challenges of the Sustainable Development (GIRE3D), Marrakech, 23-25 May 2006.

Hartogensis, O.K., De Bruin, H.A.R., Van De Wiel, 2002. Displaced-beam small aperture scintillometer test. Part II. CASES-99 stable. Boundary-Layer Meteorol. 28, 149-176.

Hatfield, J.L., Reginato, R.J., Idso, S.B., 1983. Comparison of longwave radiation calculation methods over the United States. Water Resour. Res. 19, 285-288.

Hill, R.J., Clifford, S.F., Lawrence, R.S., 1980. Refractive index and absorption fluctuations in the infrared caused by temperature, humidity and pressure fluctuations. J. Opt. Soc. Am. 70, 1192-1205.

Hoedjes, J.C.B., Zuurbier, R.M., Watts, C.J., 2002. Large aperture scintillometer used over a homogeneous irrigated area, partly affected by regional advection. Boundary-Layer Meteorol. 105, 99-117.

Horst, T.W., Weil, J.C., 1992. Footprint estimation for scalar flux measurements in the atmospheric surface layer. BoundaryLayer Meteorol. 59, 279-296.

Horst, T.W., Weil, J.C., 1994. How far is far enough? The fetch requirements for micrometeorological measurement of surface fluxes. J. Atmos. Oceanic Technol. 11, 1018-1025.

Idso, S.B., 1981. A set of equations for full spectrum and 8 to $14 \mathrm{~mm}$ and 10.5 to $12.5 \mathrm{~mm}$ thermal radiation from cloudless skies. Water Resour. Res. 17, 295-304.

Jones, H.G., Archer, N., Rotenberg, E., Casa, R., 2003. Radiation measurement for plant ecophysiology. J. Exp. Bot. 54, 879889.

Kohsiek, W., Meijninger, W.M.L., De Bruin, H.A.R., Beyrich, F., 2006. Saturation of the large aperture scintillometer. Boundary-Layer Meteorol. 121, 111-126.

Kowalik, P.J., Turner, N.C., 1983. Diurnal changes in the water relations and transpiration of a soybean crop simulated during the development of water deficit. Irrig. Sci. 4, 225238.

Kustas, W.P., Daughtry, C.S.T., 1989. Estimation of the soil heat flux/net radiation ratio from spectral data. Agric. For. Meteorol. 49, 205-223.

Meijninger, W.M.L., Green, A.E., Hartogensis, O.K., Kohsiek, W., Hoedjes, J.C.B., Zuurbier, R.M., De Bruin, H.A.R., 2002a. Determination of area-averaged water vapour fluxes with a large aperture and radio wave scintillometers over a heterogeneous surface-flevoland field experiment. Boundary-Layer Meteorol. 105, 63-83.

Meijninger, W.M.L., Hartogensis, O.K., Kohsiek, W., Hoedjes, J.C.B., Zuurbier, R.M., De Bruin, H.A.R., 2002b. Determination of area-averaged sensible heat fluxes with a large aperture scintillometer over a heterogeneous surface - Flevoland field experiment. Boundary-Layer Meteorol. 105, 37-62.

Mermier, M., Seguin, B., 1976. Le rayonnement net à AvignonMontfavet, INRA, Station de bioclimatologie d'Avignon, Note M/76/4, 14 pp.

Monteith, J.L., 1973. Principles of Environmental Physics. Edward Arnold Press, 241 pp.

Monteith, J.L., Unsworth, M.H., 1990. Principles of Environmental Physics. Edward Arnold, London, 291pp.

Moore, C.J., 1986. Frequency response corrections for eddy correlation systems. Boundary-Layer Meteorol. 37, 17-35.

Norman, J.M., Kustas, W.P., Humes, K.S., 1995. A two-source approach for estimating soil and vegetation energy fluxes from observations of directional radiometric surface temperature. Agric. For. Meteorol. 77, 263-293.

Ochs, G.R., Wilson, J.J., 1993. A second-generation large-aperture scintillometer, NOAA Tech. Memo, ERL WPL-232. NOAA Environmental Research Laboratories, Boulder, CO.
Olioso, A., 1992. Simulation des échanges d'énergie et de masse d'un couvert végétal dans le but de relier la transpiration et la photosynthèse aux mesures de réflectance et de température de surface, Doctorat thesis, Université de Montpellier, France, 250 pp.

Ortega-farias, S., Antonioletti, R., Olioso, A., 2000. Net radiation model evolution at an hourly time step for Mediterranean conditions. Agronomie 20, 157-164.

Panofsky, H.A., Dutton, J.A., 1984. Atmospheric Turbulence: Models and Methods for Engineering Applications. John Wiley \& Sons, New York, 397 pp.

Poulos, G.S., Fritts, D.C., Blumen, W., Bach Jr., W.D., 2000. CASES-99 field experiment: an overview. In: 14th Symposium on Boundary Layer and Turbulence, 7-11 August, Aspen, CO.

Schotanus, P., Nieuwstadt, F., De Bruin, H.A.R., 1983. Temperature measurement with a sonic anemometer and its application to heat and moisture fluxes. Boundary-Layer Meteorol. 26, 81-93.

Stull, R.B., 1988. An Introduction to Boundary Layer Meteorology, Atmospheric Sciences. Library. Kluwer Academic Publishers, $666 \mathrm{pp}$.

Su, Z., Schmugge, T., Kustas, W.P., Massman, W.J., 2001. An evaluation of two models for estimation of the roughness height for heat transfer between the land surface and the atmosphere. J. Appl. Meteorol. 40, 1951-1966.

Testi, L., Villalobos, F.J., Orgaz, F., 2004. Evapotranspiration of a young irrigated olive orchard in southerb Spain. Agric. For. Meteorol. 121, 1-18.

Thiermann, V., Grassl, H., 1992. The measurement of turbulent surface-layer fluxes by use of bichromatic scintillation. Boundary-Layer Meteorol. 58, 367-389.

Twine, T.E., Kustas, W.P., Norman, J.M., Cook, D.R., Houser, P.R., Meyers, T.P., Prueger, J.H., Starks, P.J., Wesly, M.L., 2000. Correcting Eddy-covariance flux underestimates over a grassland. Agric. For. Meteorol. 103, 279-300.

Van Dijk, A., Kohsiek, W., De Bruin, H.A.R., 2003. Oxygen sensitivity of krypton and lymann- $\boldsymbol{\alpha}$ hygrometers. J. Atmos. Oceanic Technol. 20, 143-151.

Villalobos, F.J., Orgaz, F., Testi, L., Fereres, E., 2000. Measurement and modeling of evapotranspiration of olive (Olea europaea L.) orchards. Eur. J. Agron. 13, 155-163.

Vogt, R., Christen, A., Pitacco, A., 2004. Scintillometer measurements in a Cork Oak and an Olive tree plantation. In: 26th Conference on Agricultural and Forest Meteorology, 23-27 August, Vancouver, BC, Canada.

Webb, E.K., Pearman, G.I., Leunin, R., 1980. Correction of flux measurements for density effects due to heat and water vapor transfer. Q. J. R. Meteorol. Soc. 106, 85-100.

Wesely, M.L., 1976. The combined effect of temperature and humidity fluctuations on refractive index. J. Appl. Meteorol. 15, 43-49.

Wilczak, J., Oncley, S., Stage, S.A., 2001. Sonic anemometer tilt correction algorithms. Boundary-Layer Meteorol. 99, 127150.

Williams, D.G., Cable, W., Hultine, K., Yepez, E., Er-Raki, S., Hoedjes, J.C.B., Boulet, G., De Bruin, H.A.R., Chehbouni, A., Timouk, F., 2003. Suivi de la répartition de l'évapotranspiration dans une oliveraie (Olea europaea L.) à l'aide des techniques de l'eddy covariance, des flux de sève et des isotopes stables. Vèmes Journées de l'Ecologie Fonctionnelle, 12 au 14 Mars 2003 à Nancy.

Wyngaard, J.C., Izumi, Y., Collins Jr., S.A., 1971. Behavior of the refractive index structure parameter near the ground. J. Opt. Soc. Am. 61, 1646-1650. 